\title{
Effect of guideline on positioning of neonates in the neonatal intensive care unit
}

\author{
Soniya PS*
}

*Corresponding author:

Soniya PS, M.Sc (N), Asst. Professor, Canossa College of nursing, Cherukunnu, Kannur, Kerala, India

Email: sonusebfdcc@yahoo.com $\underline{\text { ORCID }}$

\section{Information about the article:}

Received: Jan. 17, 2019

Accepted: Feb. 20, 2019

Published online: Dec. 27, 2019

Publisher

Nepal Health Research Society, Bahundhara -6, Gokarnesowor Municipality, Kathmandu, Nepal

eISSN 2382-5545, ISSN 2676-1343 (Print)

(C) The Author(s). 2019

Content licensing: CC BY 4.0

\begin{abstract}
\section{Background}

Developmentally Supportive Care is a broad category of interventions that is designed to minimize the stress of the NICU environment which include care such as control of external stimuli, clustering of nursery care activities, and positioning or swaddling of the preterm infant so as to provide a sense of containment similar to the intrauterine experience. The preterm neonates often lack adequate muscle tone and are at risk for developing abnormal movement pattern as well as skeleton deformation. Positioning is one of the important aspects of Developmentally Supportive Care to keep the baby comfortable. It is a basic neonatal nursing care and includes keeping the baby in supine, prone and side lying. As postural stability is a foundational milestone for motor development and premature infants are unable to exhibit postural stability without support, standardizing the definition of optimal positioning will lead to consistency in practice. A neonatal positioning guideline implemented in NICU will help in the growth and development of preterm neonates.
\end{abstract}

\section{Materials and Methods}

A prospective study was conducted in NICU of a tertiary medical College Hospital, Bangalore. It was an experimental study. Neonatal nurses who were involved in preterm infants care were selected by purposive sampling. Sample size was calculated based on the study by Jeansonetal. Pretest and posttest practices were assessed by taking the average of two observations for each nurse using infant positioning Assessment tool (IPAT). The nurses were trained by lecture followed by practical demonstration of neonatal positioning guidelines. After one week post test was repeated. Paired T test was used for comparing the positioning in pre and post intervention.

\section{Results}

Pre-test practice concludes that $100 \%$ (25) of the staff nurses were in the category of 'need for repositioning' and 100\% (25) of the nurses were in the category of 'acceptable positioning' in post-test $(\mathrm{P}<0.001)$ with respect to all the positioning parameters. The mean Pretest score was 4.14 \pm 1.02 and post test mean score was $10.17 \pm 0.57(\mathrm{P}<0.001)$. There was a significant association in practice score with respect to years of experience in NICU $(\mathrm{P}<0.05)$.

\section{Conclusion}

There was a significant improvement in the infant positioning scores in the post test after introducing the positioning guidelines and training the nurses, compared to the pretest scores.

\section{Keywords}

Developmental care, positioning, pre-term infants 